\title{
Dextran Sodium Sulphate-Induced Gastrointestinal Injury Further Aggravates the Impact of Galantamine on the Gastric Myoelectric Activity in Experimental Pigs
}

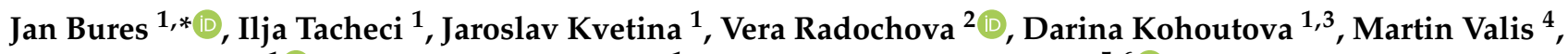 \\ Stanislav Rejchrt ${ }^{1}$, Veronika Knoblochova ${ }^{1}$ and Jana Zdarova Karasova ${ }^{5,6}{ }^{1}$ \\ 1 2nd Department of Internal Medicine-Gastroenterology, Charles University, Faculty of Medicine in Hradec \\ Kralove and University Hospital, 50003 Hradec Kralove, Czech Republic; tacheci@gmail.com (I.T.); \\ kvetina.jaroslav@seznam.cz (J.K.); darina.kohoutova@rmh.nhs.uk (D.K.); rejchrt@lfhk.cuni.cz (S.R.); \\ veronika.knoblochova@fnhk.cz (V.K.) \\ 2 Animal Laboratory, Faculty of Military Health Sciences, University of Defence, 50001 Hradec Kralove, \\ Czech Republic; vera.radochova@unob.cz \\ 3 The Royal Marsden NHS Foundation Trust, London SW3 6JJ, UK \\ 4 Department of Neurology, Charles University, Faculty of Medicine in Hradec Kralove and University \\ Hospital, 50003 Hradec Kralove, Czech Republic; martin.valis@fnhk.cz \\ 5 Department of Toxicology and Military Pharmacy, Faculty of Military Health Sciences, University of Defence, \\ 50001 Hradec Kralove, Czech Republic; zdarova.jana@gmail.com \\ check for \\ updates \\ Citation: Bures, J.; Tacheci, I.; \\ 6 Biomedical Research Centre, University Hospital, 50005 Hradec Kralove, Czech Republic \\ * Correspondence: bures@lfhk.cuni.cz
}

Kvetina, J.; Radochova, V.;

Kohoutova, D.; Valis, M.; Rejchrt, S.; Knoblochova, V.; Zdarova Karasova, J. Dextran Sodium Sulphate-Induced Gastrointestinal Injury Further Aggravates the Impact of Galantamine on the Gastric Myoelectric Activity in Experimental Pigs. Pharmaceuticals 2021, 14, 590. https://doi.org/10.3390/ph14060590

Academic Editor: Lusine Danielyan and Huu Phuc Nguyen

Received: 18 April 2021

Accepted: 9 June 2021

Published: 18 June 2021

Publisher's Note: MDPI stays neutral with regard to jurisdictional claims in published maps and institutional affiliations.

Copyright: () 2021 by the authors. Licensee MDPI, Basel, Switzerland. This article is an open access article distributed under the terms and conditions of the Creative Commons Attribution (CC BY) license (https:// creativecommons.org/licenses/by/ $4.0 /)$.

\begin{abstract}
Galantamine has been used as a treatment for Alzheimer disease. It has a unique, dual mode of action (inhibitor of acetylcholinesterase and allosteric modulator of nicotinic acetylcholine receptors). Nausea (in about 20\%), vomiting (10\%) and diarrhoea (5-7\%) are the most common side effects. The aim of this study was to assess the effect of galantamine on porcine gastric myoelectric activity without (Group A) and with (Group B) dextran sodium sulphate (DSS)-induced gastrointestinal injury. Galantamine hydrobromide was administrated to twelve pigs as a single intragastric dose (24 mg). Gastric myoelectric activity was investigated by electrogastrography (EGG). Basal (15 min before galantamine administration) and study recordings after galantamine administration (300 $\mathrm{min}$ ) were evaluated using a running spectral analysis. Results were expressed as dominant frequency of gastric slow waves and power analysis (areas of amplitudes). Altogether, 3780 one-minute EGG recordings were evaluated. In Group A, power was steady from basal values for $180 \mathrm{~min}$, then gradually decreased till $270 \mathrm{~min}(p=0.007)$. In Group $\mathrm{B}$, there was a rapid gradual fall from basal values to those after $120 \mathrm{~min}(p=0.007)$ till $300 \mathrm{~min}(p<0.001)$. In conclusion, galantamine alone revealed an unfavourable effect on porcine myoelectric activity assessed by gastric power. It can be a plausible explanation of galantamine-associated dyspepsia in humans. DSS caused further profound decrease of EGG power. That may indicate that underlying inflammatory, ischaemic or NSAIDs-induced condition of the intestine in humans can have aggravated the effect of galantamine on gastric myoelectric activity.
\end{abstract}

Keywords: Alzheimer disease; galantamine; electrogastrography; experimental pigs; gastric motor dysmotility; small bowel transit time; wireless capsule enteroscopy

\section{Introduction}

Galantamine has been used as a treatment for Alzheimer disease and myasthenia gravis [1-5]. It has a unique, dual mode of action, it works as a reversible competitive inhibitor of acetylcholinesterase and a modulator of nicotinic acetylcholine receptors (type I positive allosteric modulator of $\alpha 7 \mathrm{nACh}$ receptors). Galantamine inhibits the breakdown of acetylcholine by binding to the active site on acetylcholinesterase. This inhibitory 
effect is particularly important in the cerebral areas with the most affected cholinergic neurotransmission in Alzheimer disease (i.e., frontal cortex and hippocampus). Peak serum concentration after its oral administration is reached in one hour in humans, halflife elimination lasts about $7 \mathrm{~h}$ [1-5]. Further, galantamine acts as a weak competitive reversible acetylcholinesterase inhibitor in the gastrointestinal tract [6]. Galantamine can also influence the immune system through a "cholinergic anti-inflammatory pathway [5].

Nausea (occurring in about $20 \%$ of chronic users), vomiting $(10 \%)$ and diarrhoea $(5-7 \%)$ are the most common gastrointestinal adverse side effects [7-14]. Pathogenesis of these motility disorders has not been fully clarified yet. Ageing has a significant impact on the function of the gastrointestinal tract, even in healthy seniors. Its function can be further deteriorated by an underlying inflammatory or ischemic condition of the intestine. Experimental dextran sodium sulphate (DSS)-induced injury affects morphology and/or function of different parts of the gastrointestinal tract, including the small bowel [15-25], and thus, interfere with the absorption and pharmacokinetics of different drugs. In experimental setting, DSS can also induce functional gastric motor disorder [26].

Surface electrogastrography (EGG) is a non-invasive method for the assessment of gastric myoelectrical activity [27-32]. Our group has demonstrated that EGG is also reliable in experimental pigs [26,33]. Porcine surface EGG is fully comparable with that one recorded in healthy humans [34]. EGG has also been used for the evaluation of gastric motility influenced by inhibitors and modulators of acetylcholinesterase in experimental pigs $[35,36]$.

The aim of this study was to assess the effect of a single dose of galantamine on porcine gastric myoelectric activity with and without DSS-induced injury.

\section{Results}

Altogether, 3780 one-minute EGG recordings were evaluated, each in dominant frequency (DF) and power. A total of 41 outliers (1.1\% of all recordings; from various time intervals of different animals in both groups) were excluded from the final evaluation of the EGG power. In Group A, DF raised gradually from basal values (median 1.06; interquartile range $0.70-1.41 \mathrm{cpm})$ significantly after $60 \mathrm{~min}(1.17 ; 0.94-1.41 \mathrm{cpm} ; p=0.016)$ and $210 \mathrm{~min}$ $(1.41 ; 0.94-2.81 \mathrm{cpm} ; p<0.001)$, Figure 1. In Group B, DF increased from basal values (1.17; $0.94-2.81 \mathrm{cpm})$ rapidly within $30 \mathrm{~min}(2.58 ; 1.29-3.28 \mathrm{cpm} ; p<0.001)$ and sustained significantly higher till the end of recording $(2.11 ; 1.17-3.3 \mathrm{cpm} ; p<0.001)$, Figure 2. In Group A, power was steady from basal values (median 2264; IQR 901-7743 $\mu \mathrm{V}^{2}$ ) for $180 \mathrm{~min}$, then gradually decreased till $270 \mathrm{~min}\left(1461 ; 558-3393 \mu \mathrm{V}^{2} ; p=0.007\right)$, Figure 3. In Group B, there was a rapid gradual fall from basal values $\left(1919 ; 690-5646 \mu \mathrm{V}^{2}\right)$ to those after $120 \mathrm{~min}$ (1297; $\left.648-535 \mu \mathrm{V}^{2} ; p=0.007\right)$ till $300 \mathrm{~min}\left(1216 ; 315-2740 \mu \mathrm{V}^{2} ; p<0.001\right)$, Figure 4 . Basal values of DF were significantly lower in Group A compared to Group B $(p=0.004)$. DF was lower in Group A during the whole study period, the most distinct differences between the groups were identified after $30 \mathrm{~min}(p<0.001)$ and from 105 to $120 \mathrm{~min}$ after the administration of galantamine $(p<0.001)$, see Figures 1 and 2. Basal values of the EGG power of both groups were not significantly different $(p=0.336$; power 0.365$)$, see Figures 3 and 4 . No gross gastrointestinal pathology was revealed on autopsy in any animal tested. 


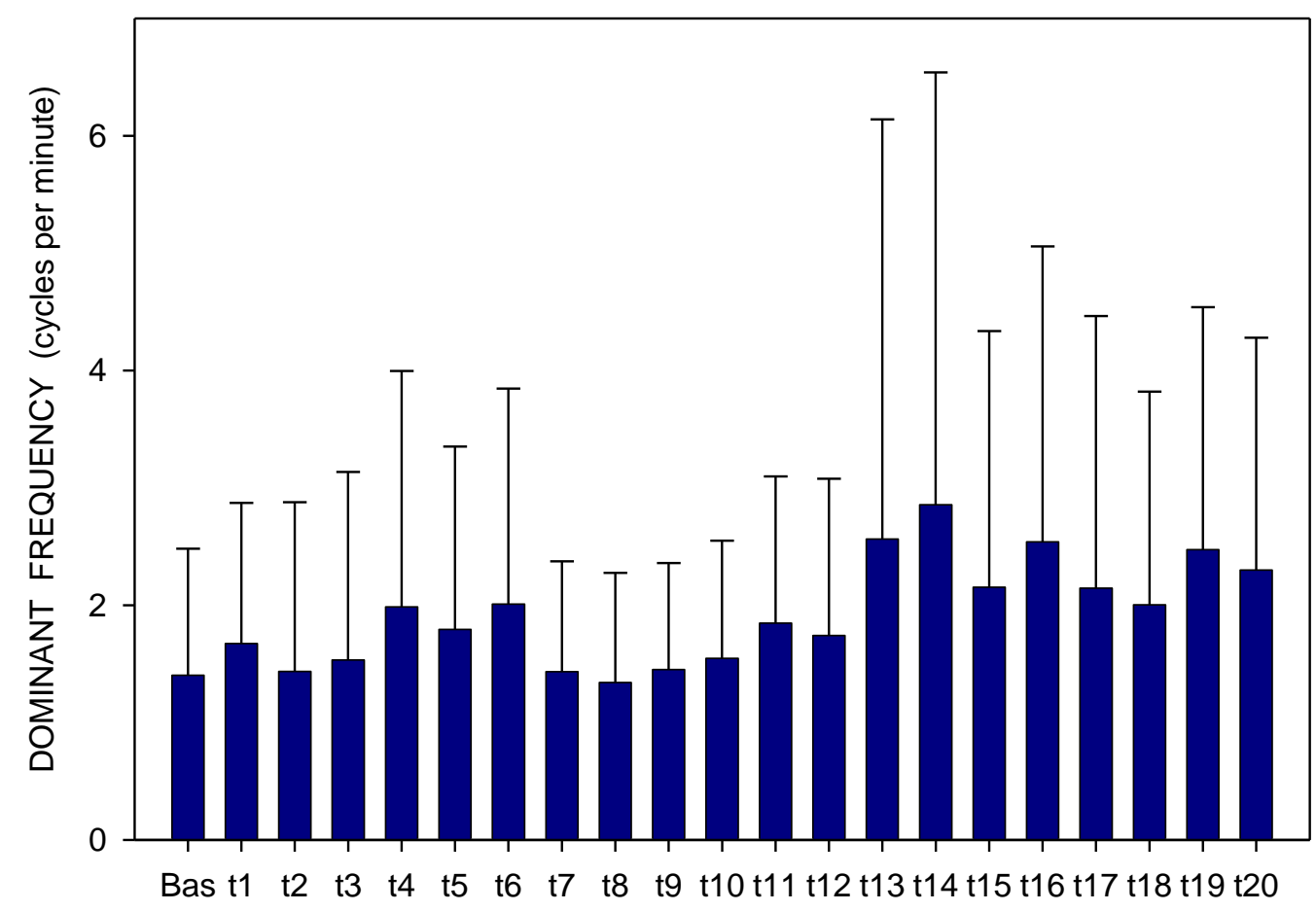

Figure 1. Electrogastrography. Dominant frequency before and after a single intragastric dose of $24 \mathrm{mg}$ galantamine (mean + standard deviation). Explanatory note: Bas: 15-min basal recording before galantamine administration; tn: 15-min study recordings after galantamine administration ( $\mathrm{t} 1$ : time interval between 0-15 min ... t20: time interval between 286-300 min).

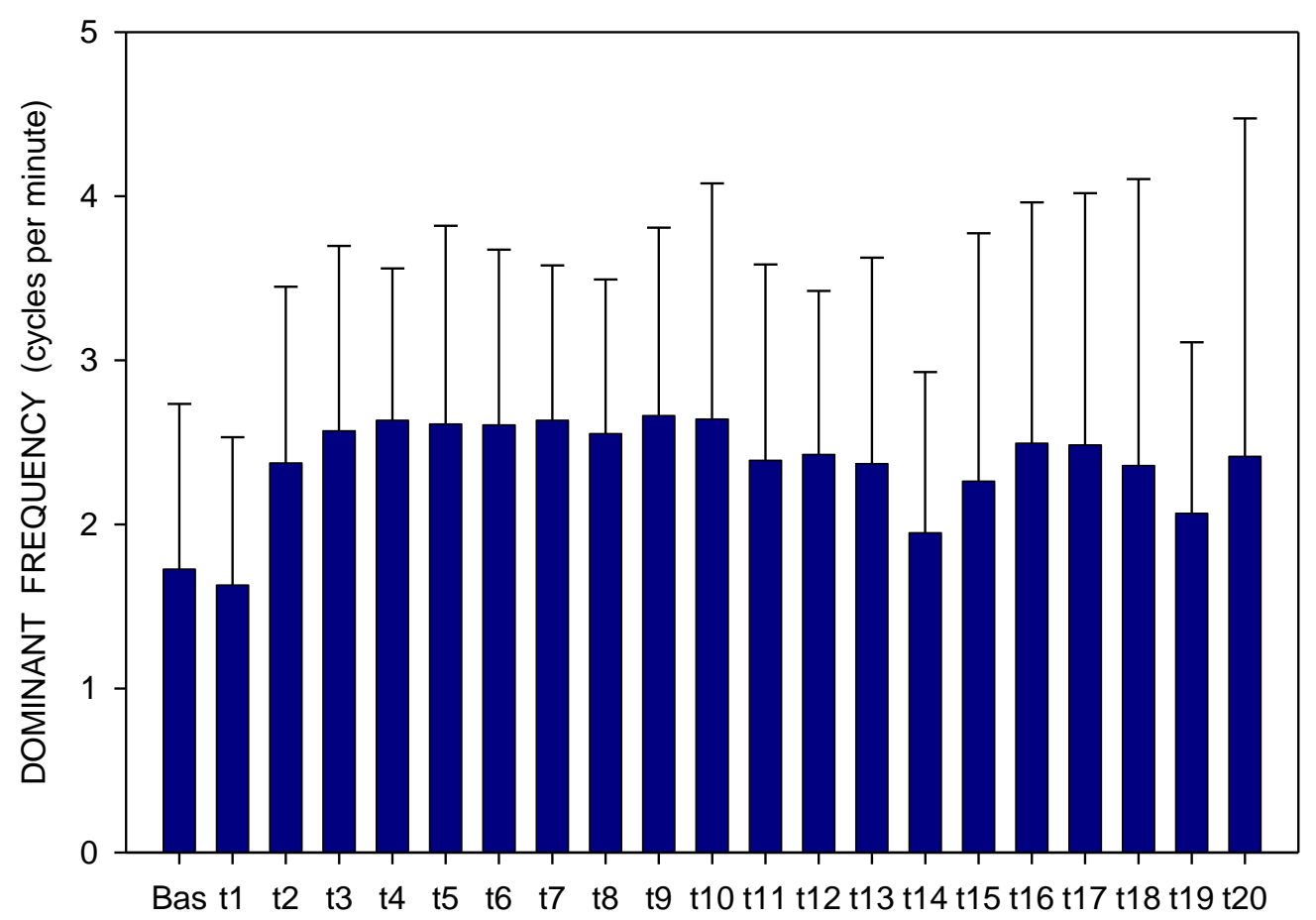

Figure 2. Electrogastrography. Dominant frequency before and after a single intragastric dose of $24 \mathrm{mg}$ galantamine in animals with previous 7-day administration of dextran sodium sulphate (mean + standard deviation). Explanatory note: Bas: 15-min basal recording before galantamine administration; t: 15-min study recordings after galantamine administration (t1: time interval between 0-15 min ... t20: time interval between 286-300 $\mathrm{min}$ ). 


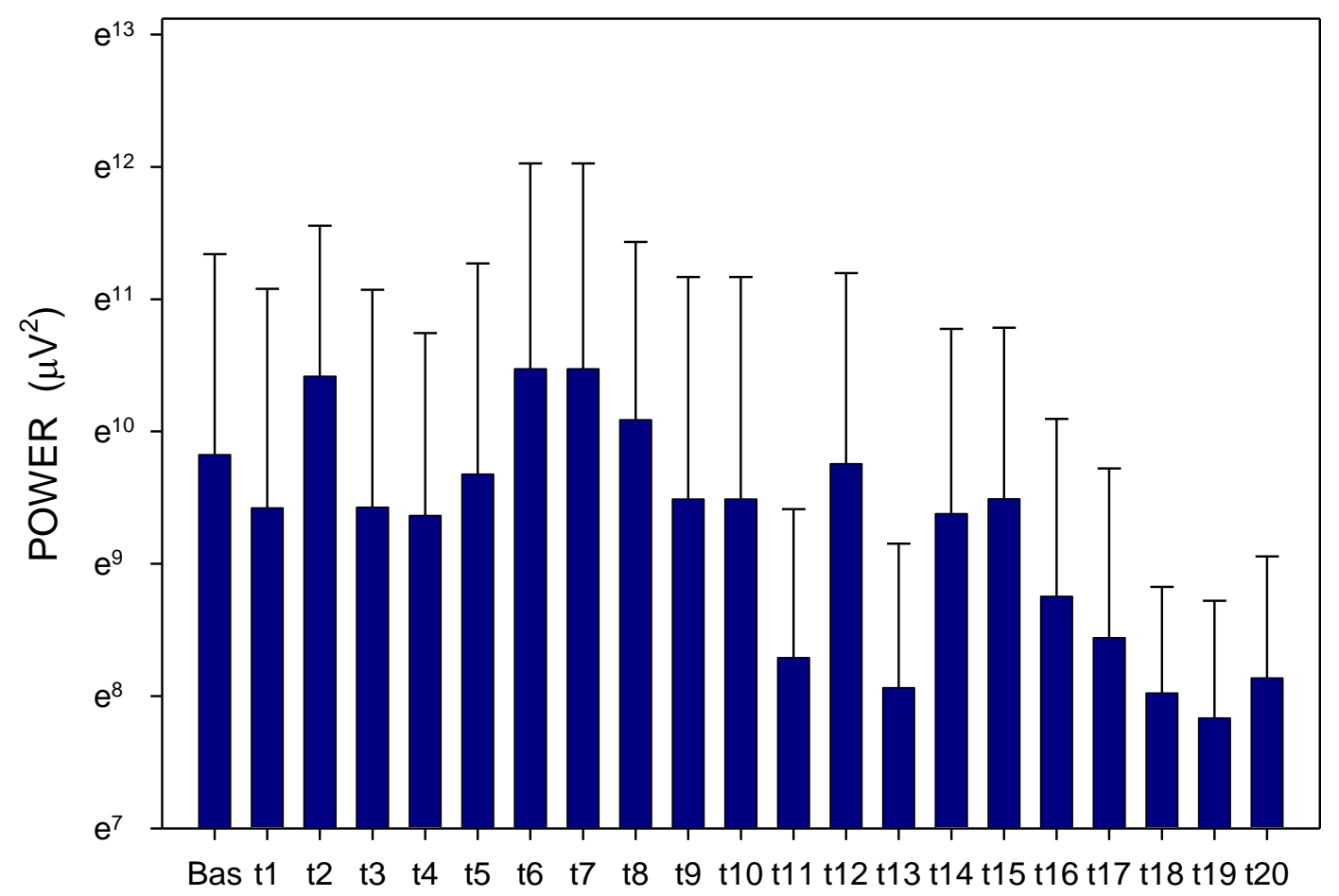

Figure 3. Electrogastrography. EGG power before and after a single intragastric administration of $24 \mathrm{mg}$ galantamine (mean + standard deviation). Outliers omitted. Axis Y: natural logarithm scale. Explanatory note: Bas: 15-min basal recording before galantamine administration; $\mathrm{t}$ : 15-min study recordings after galantamine administration ( $\mathrm{t} 1$ : time interval between 0-15 $\mathrm{min}$... t20: time interval between 286-300 $\mathrm{min}$ ).

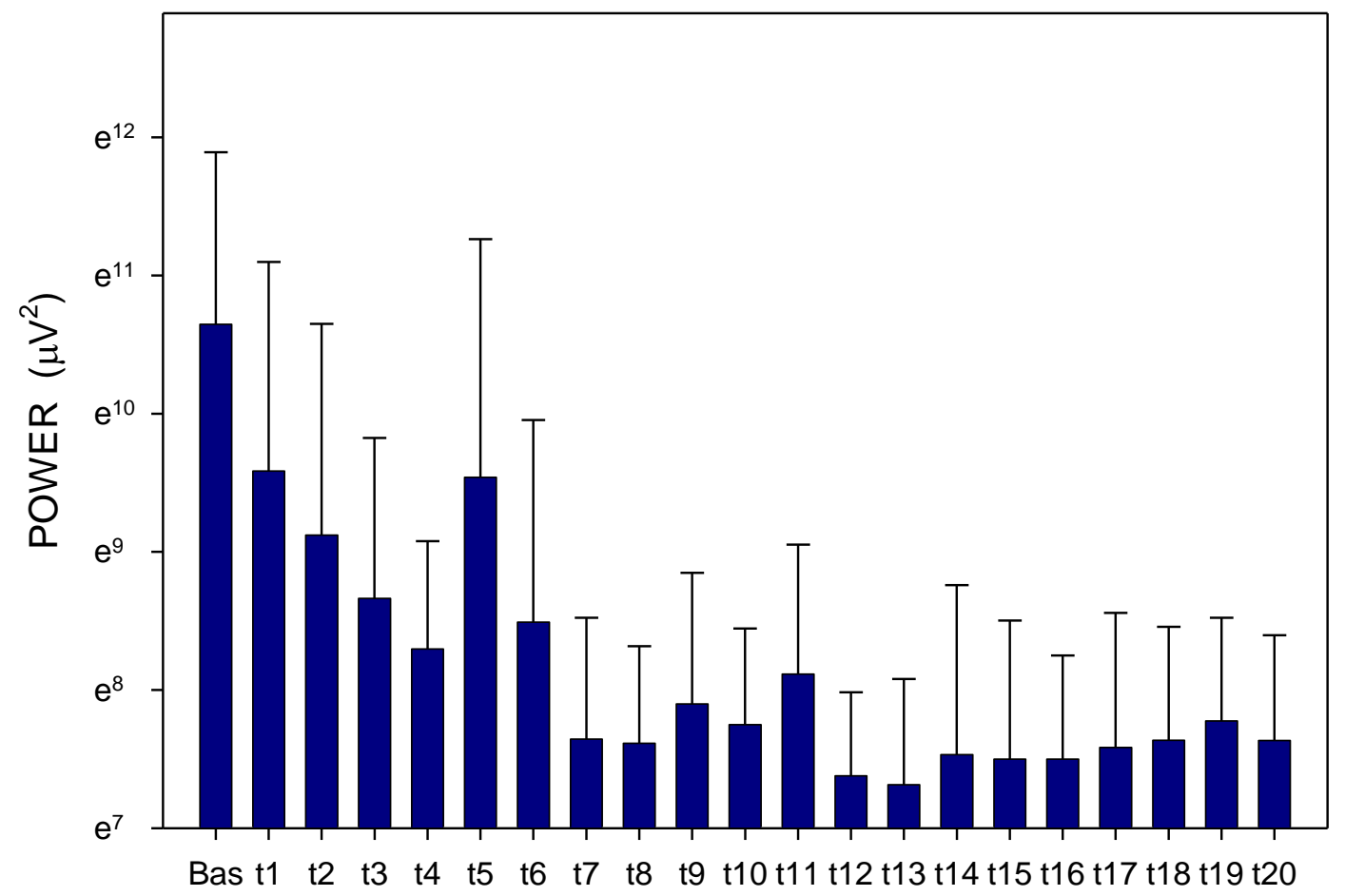

Figure 4. Electrogastrography. EGG power before and after a single intragastric administration of $24 \mathrm{mg}$ galantamine in animals with previous 7-day administration of dextran sodium sulphate (mean + standard deviation). Outliers omitted. Axis Y: natural logarithm scale. Explanatory note: Bas: 15-min basal recording before galantamine administration; t: 15-min study recordings after galantamine administration ( $\mathrm{t} 1$ : time interval between $0-15 \mathrm{~min} . . . \mathrm{t} 20$ : time interval between 286-300 $\mathrm{min})$. 
Wireless capsule enteroscopy enabled successful investigation of the entire small bowel in all animals. All endoscopic findings were normal in all pigs (Figures 5 and 6). Small bowel transit time of particular animals were: 205, 322, 592, 288, 421 and $445 \mathrm{~min}$ (mean $379 \pm 137$; median 371.5).

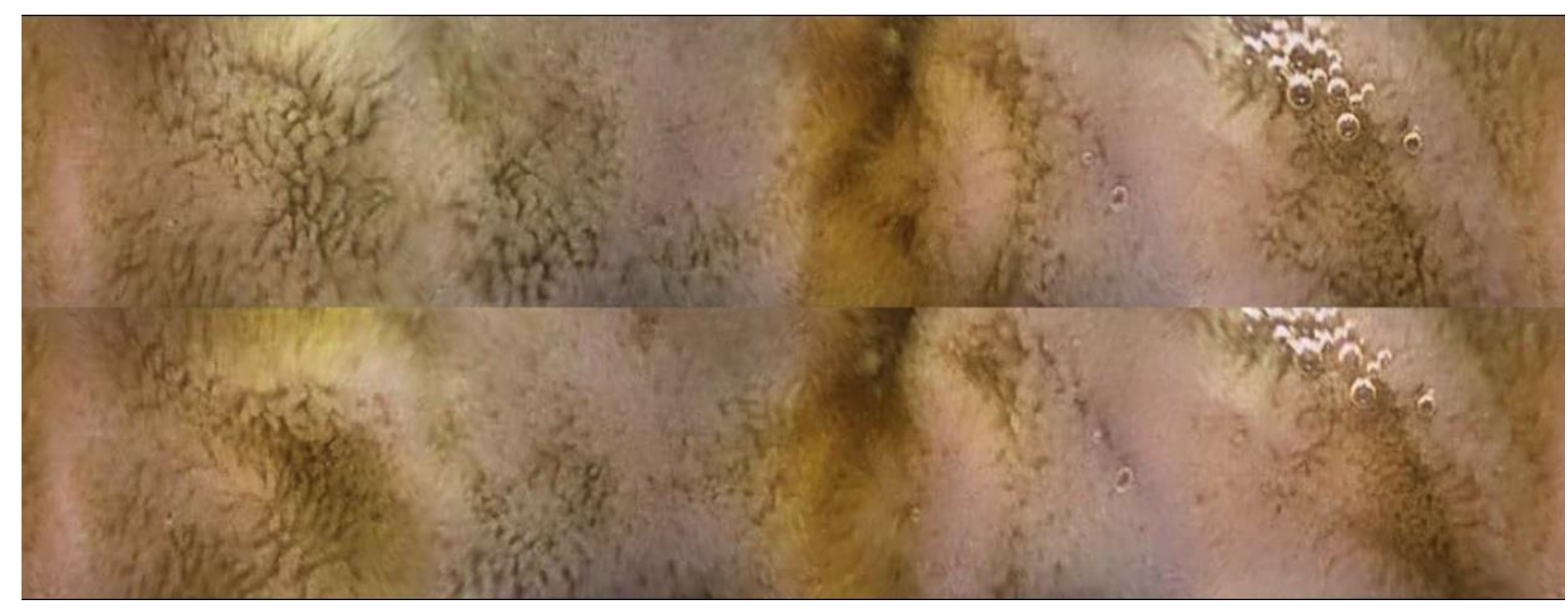

Figure 5. Wireless capsule enteroscopy. Normal jejunum.

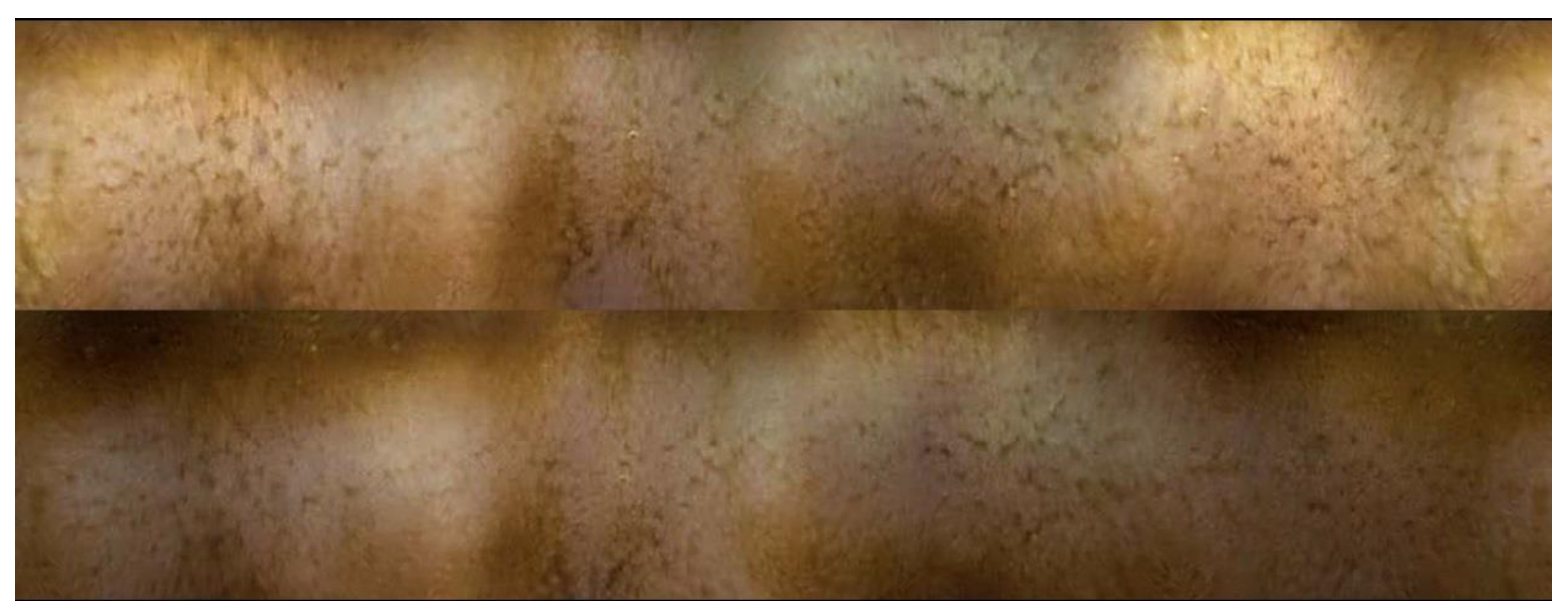

Figure 6. Wireless capsule enteroscopy. Normal ileum.

Animals were split according to small bowel transit time into subgroups of shorter (3 pigs; $272 \pm 60 \mathrm{~min}$ ) and longer transit time (3 pigs; $486 \pm 93 \mathrm{~min}$ ). Dominant frequency and power were assessed in these two subgroups separately (Figures 7-10). There was a clear trend towards lower values of dominant frequency in pigs with a shorter transit time. Most prominent significant differences were revealed in time intervals t10 (median 1.17 vs. 3.52; $p<0.001$ ), t14 (median 0.94 vs. 3.05; $p<0.001$ ), t19 (median 0.94 vs. $2.81 ; p<0.001$ ) and t20 (median 0.94 vs. 2.81 cycles per minute; $p<0.001$ ). There were significant differences of the EGG power in animals with a shorter transit time compared to pigs with a longer transit time. Most prominent differences were found in time intervals t2 (median $1804 \mathrm{vs}$. 4313; $p=0.003$ ), $\mathrm{t} 11$ (median 236 vs. 2037; $p<0.001$ ) and $\mathrm{t} 16$ (median 188 vs. $2226 \mu \mathrm{V}^{2}$; $p<0.001)$. 


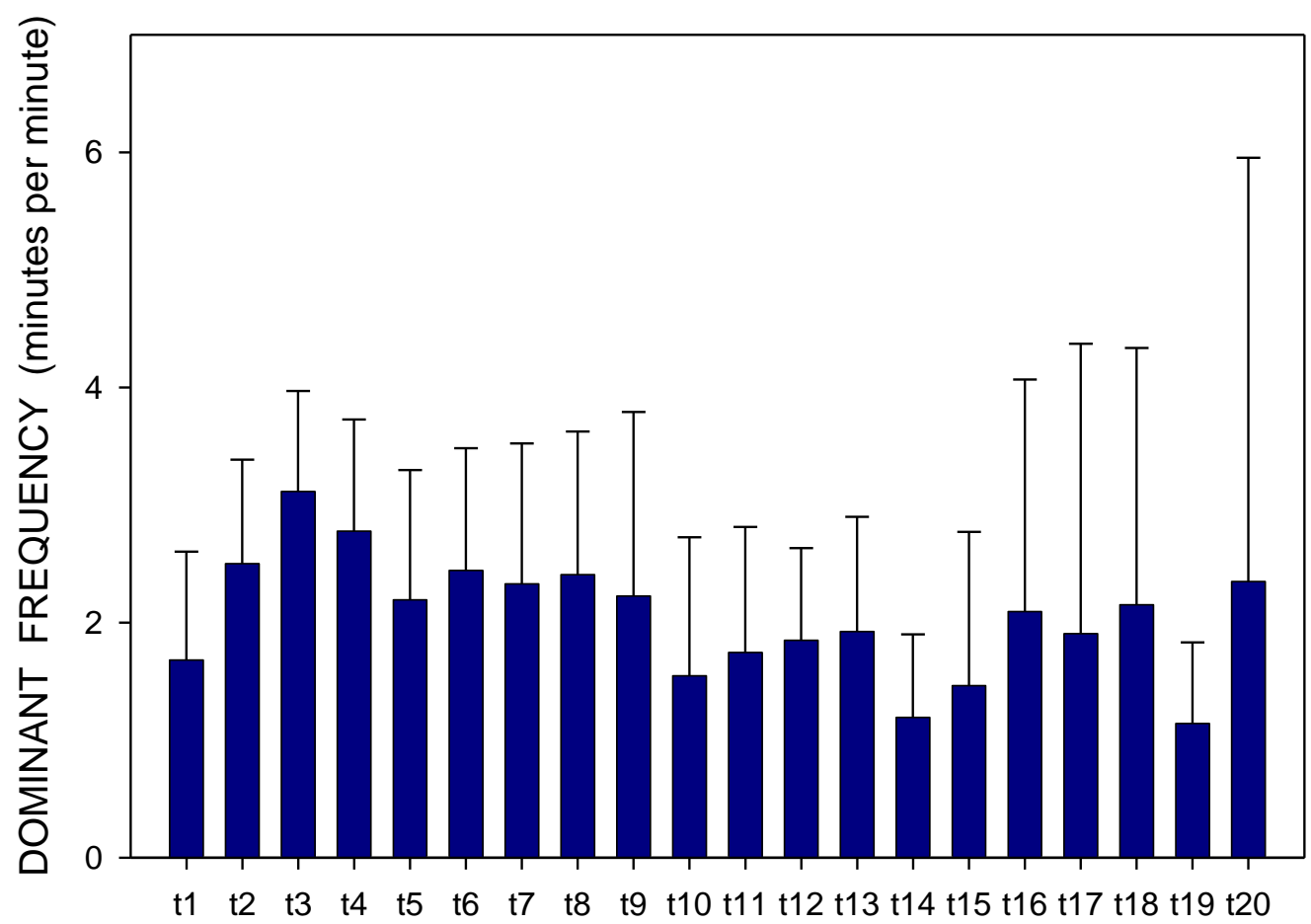

Figure 7. Electrogastrography. Dominant frequency in animals with a shorter small bowel transit time (272 \pm 60 min); mean + standard deviation. Explanatory note: t: 15 -min study recordings after galantamine administration (t1: time interval between $0-15 \mathrm{~min} . . . \mathrm{t} 20$ : time interval between $286-300 \mathrm{~min}$ ).

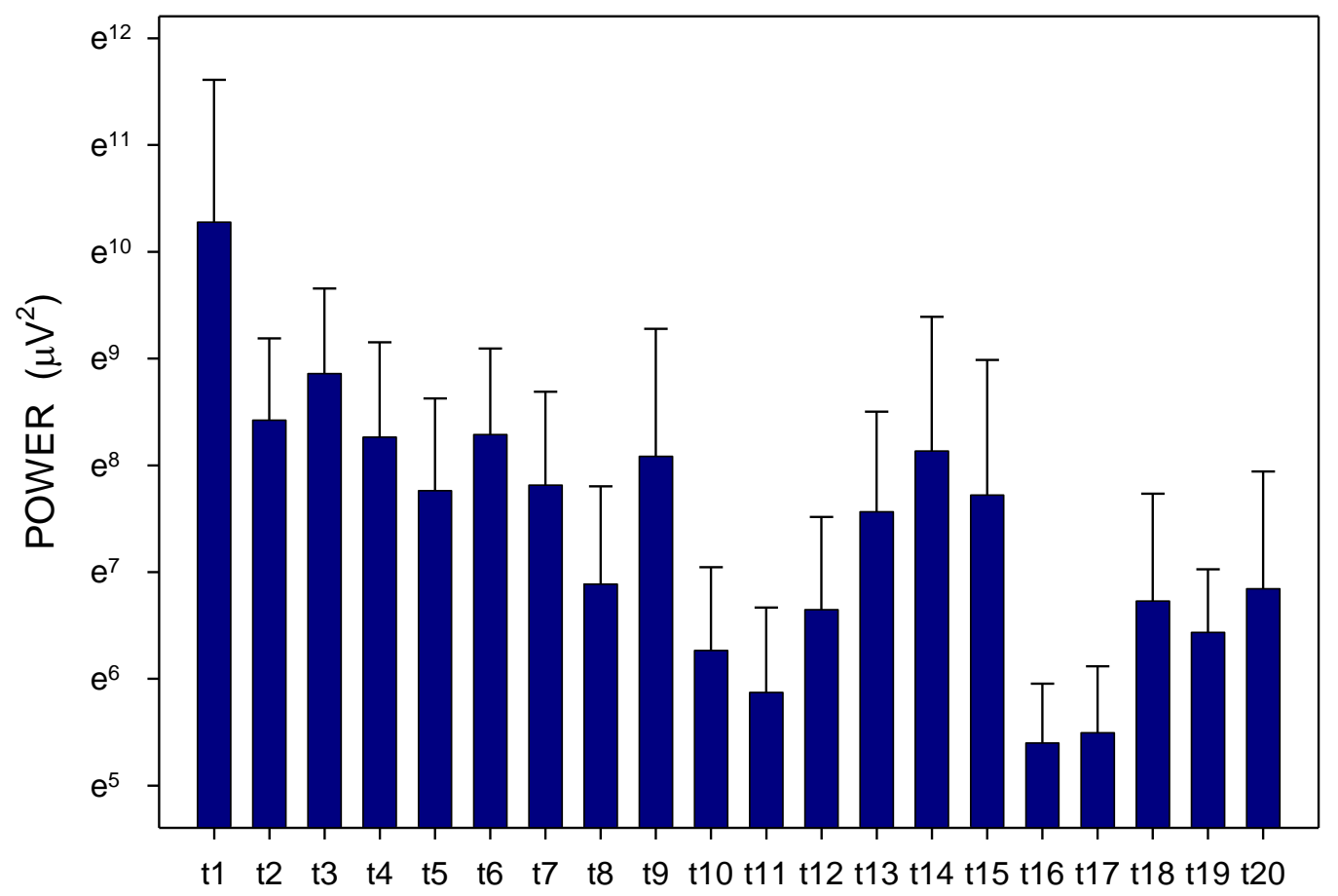

Figure 8. Electrogastrography. EGG power in animals with a shorter small bowel transit time (272 $\pm 60 \mathrm{~min})$; mean + standard deviation. Outliers omitted. Axis Y: natural logarithm scale. Explanatory note: t: 15-min study recordings after galantamine administration ( $\mathrm{t} 1$ : time interval between 0-15 min ... t20: time interval between 286-300 min). 


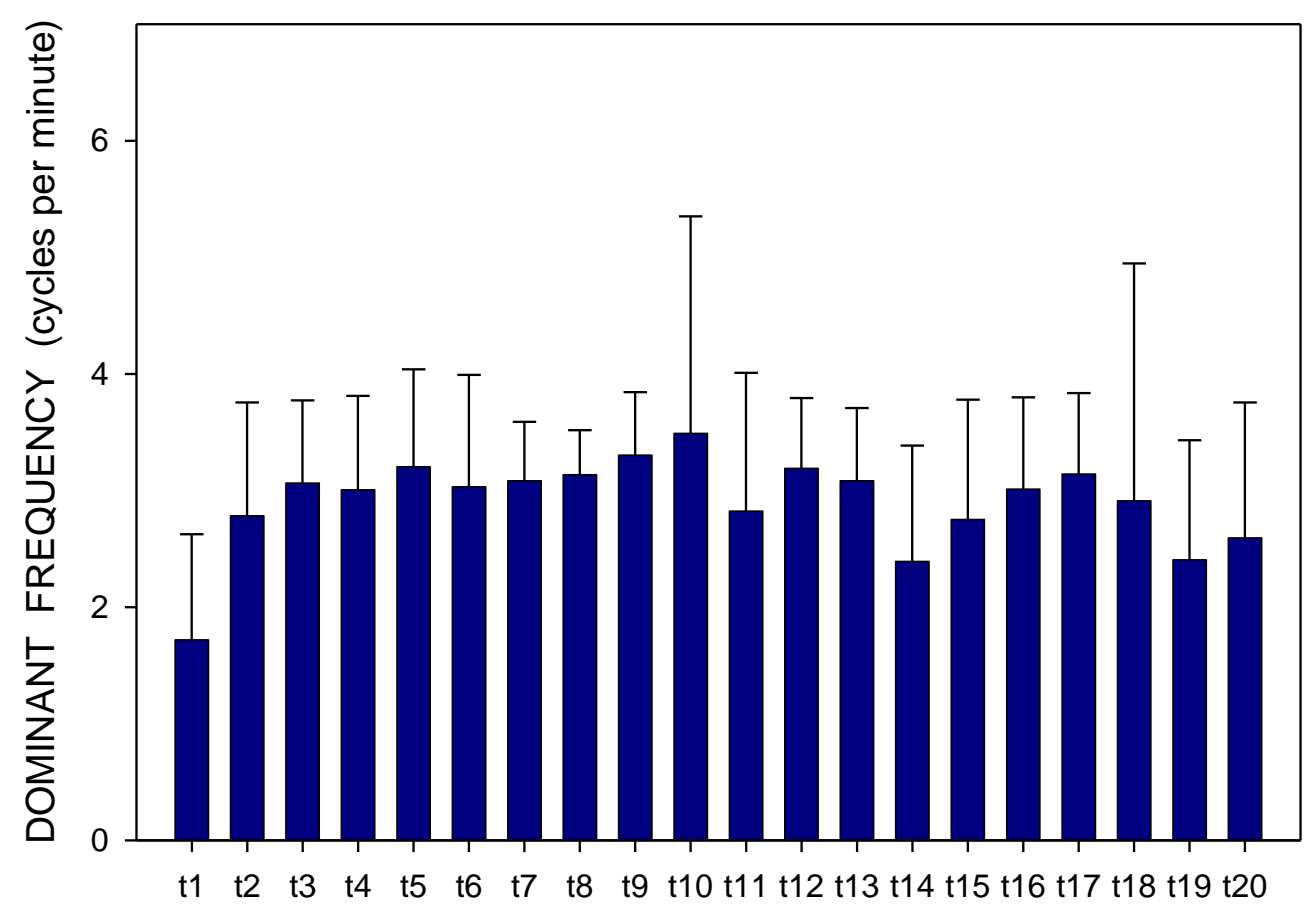

Figure 9. Electrogastrography. Dominant frequency in animals with a longer small bowel transit time (486 \pm 93 min); mean + standard deviation. Explanatory note: $\mathrm{t}$ : $15-\mathrm{min}$ study recordings after galantamine administration ( $\mathrm{t} 1$ : time interval between 0-15 $\mathrm{min}$... t20: time interval between 286-300 $\mathrm{min}$ ).

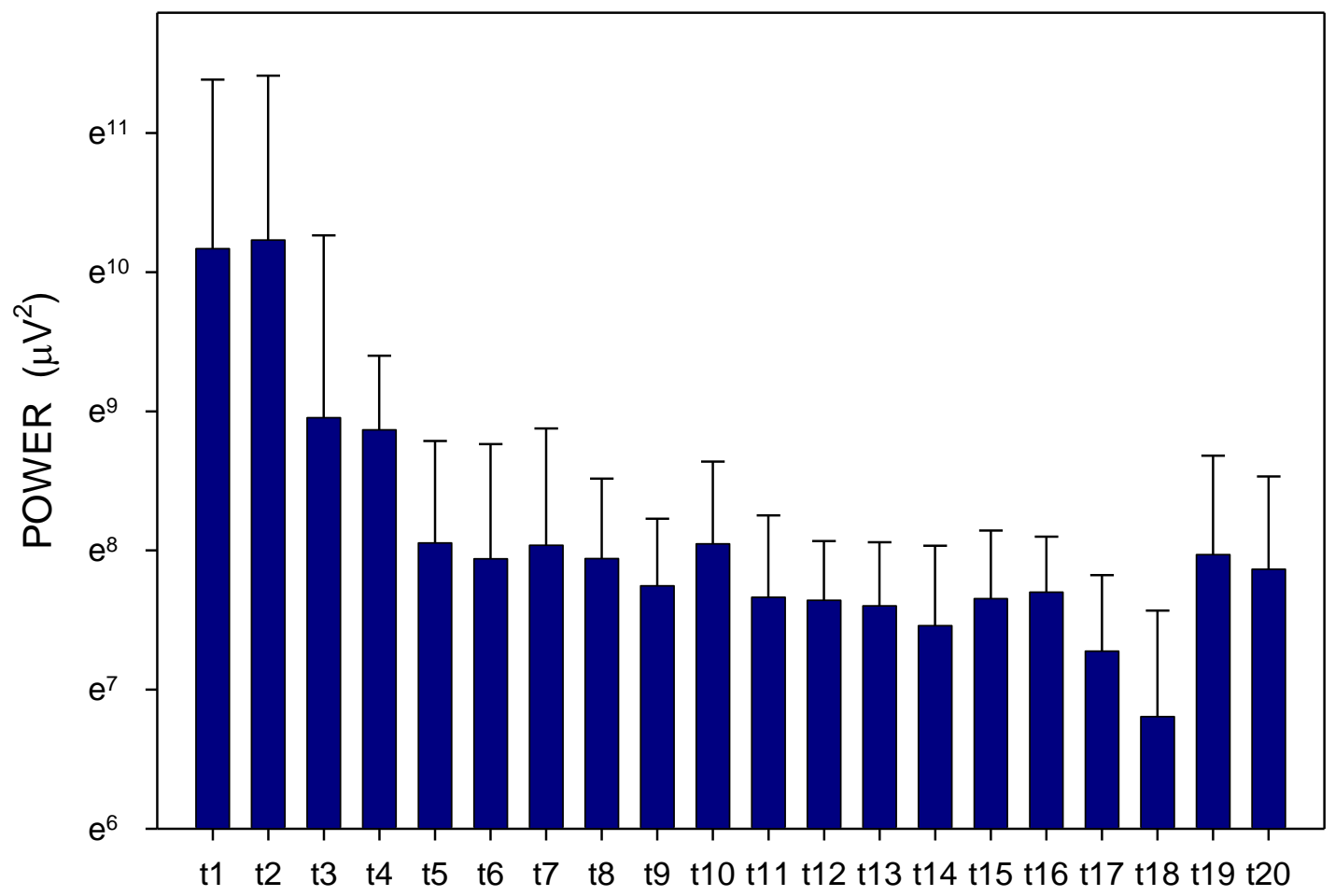

Figure 10. Electrogastrography. EGG power in animals with a longer small bowel transit time (486 \pm 93 min); mean + standard deviation. Outliers omitted. Axis Y: natural logarithm scale. Explanatory note: t: 15-min study recordings after galantamine administration ( $\mathrm{t} 1$ : time interval between 0-15 min ... t20: time interval between 286-300 min). 


\section{Discussion}

Our current study brought completely novel findings on the impact of galantamine on gastric motor function in experimental pigs. Porcine gastrointestinal physiology is similar to the human one [37,38], therefore, preclinical experimental studies may be relevant for clinical medicine. To the best of our knowledge, this is the first study evaluating effect of galantamine on the gastric motor function in experimental pigs. The impact of DSS on the entire gastrointestinal tract depends on three variables: molecular weight of DSS, daily dose and cumulative dose of DSS. Different doses of medium-molecular-weight DSS have been recommended (from 0.25 to $1.25 \mathrm{~g} / \mathrm{kg} /$ day) for induction of experimental gastrointestinal injury [15-26,39]. We intentionally decided on administration the lower dose $(0.3 \mathrm{~g} / \mathrm{kg} /$ day $)$ to induce functional but not a structural gastrointestinal injury. Basal and study values of DF were significantly higher in the group with previous DSS administration compared to the group without DSS. However, it is necessary to interpret these findings with caution as mean values of DF remained mostly within normal range between 1.5 and 3 cycles per minute.

Porcine gastric motor activity has a substantial inter-individual variability, even in experimental animals without any intervention [our data not shown]. That is why the basal recording serves as an individual control for subsequent study part in each experimental pig. We measured small bowel transit time in particular animals. We divided pigs into two subgroups, with a shorter and longer transit time and evaluated dominant frequency and power. Animals with a shorter transit time had lower values of dominant frequency and EGG power. The porcine small intestine is about $12 \mathrm{~m}$ long (twice as long compared to the human small bowel). Therefore, a sufficient reserve of an intestinal absorptive capacity can be assumed. However, small bowel transit time has an important impact on drug absorption and pharmacokinetics. In our previous study with donepezil, experimental pigs with a shorter bowel transit time had a significantly lower average plasma concentrations of donepezil compared to animals with a longer small bowel transit time [40].

It can be assumed, that the impact of galantamine on the porcine EGG power could be dose-dependent-in analogy how the cholinergic and anti-cholinergic compounds act. In our previous study, we found that high doses of atropine $(0.15 \mathrm{mg} / \mathrm{kg})$ induce an important decrease of EGG power in experimental pigs in contrast to moderate dose of atropine $(0.05 \mathrm{mg} / \mathrm{kg})$ [34]. Parkman et al. [41] studied EGG before and after a low dose of atropine in humans ( $0.6 \mathrm{mg}$ as an intravenous bolus continued by $0.25 \mathrm{mg}$ per hour i.v.). Atropine caused a decrease of EGG power under fasting condition [41]. Cardiac response to atropine in humans also depends on the dose. Atropine in a standard dose $(0.5-1 \mathrm{mg})$ increases the heart rate in healthy subjects. However, atropine can cause paradoxical heart rate slowdown when given in low doses (i.e., $<0.5 \mathrm{mg}$ ) - presumably as a result of the interactions in the central nervous system. One of the proposed mechanisms for the paradoxical bradycardia effect of atropine at low doses involves the blockade of the inhibitory presynaptic muscarinic receptors, thereby blocking a system that inhibits the parasympathetic response [42]. In our current experimental study, the course of EGG power in the second group (galantamine + DSS) was similar to that which was observed after the intramuscular administration of neostigmine in experimental pigs in a standard dose $(0.015 \mathrm{mg} / \mathrm{kg})$ [43]. Neostigmine is a parasympathomimetic compound that acts as a reversible acetylcholinesterase inhibitor. By interfering with the breakdown of acetylcholine, neostigmine indirectly stimulates both nicotinic and muscarinic receptors [43].

Turiiski et al. [44] studied the impact of galantamine on gastrointestinal motility in rats. They found several functional disturbances: hypertonia (caused by tonic contractions in smooth muscles), increased gastric and ileal peristalsis and accelerated intestinal transit time. These reactions were dose-dependent (concentrations of galantamine from $10^{-7} \mathrm{~mol} / \mathrm{L}$ to $10^{-4} \mathrm{~mol} / \mathrm{L}$ ). The tonic and phasic effect of galantamine was partially reversed by atropine or ipratropium bromide [44]. 
Galantamine may cause malignant ventricular arrhythmias (due to prolongation of QT interval and by influencing potassium channels in cardiac myocytes) [45]. We have not noticed such an event in any animal tested.

We are aware of possible limits of our study. Our current study was performed in female pigs only. Sex hormones can influence porcine gastrointestinal motor activity. In our previous experimental study on oesophageal manometry we found differences between male and female experimental pigs [46]. Our trial was designed as an acute study with higher but a single dose of galantamine. Chronic administration of galantamine with or without DSS can bring further important findings.

\section{Materials and Methods}

\subsection{Animals}

Twelve experimental adult female pigs (Sus scrofa f. domestica, hybrids of Czech White and Landrace breeds; 3-month-old; mean weight $33.2 \pm 1.9 \mathrm{~kg}$ ) were enrolled into the study. The animals were purchased from a certified breeder (Stepanek, Dolni Redice, Czech Republic; SHR MUHO 2050/2008/41). The pigs were housed in an accredited vivarium (Faculty of Military Health Sciences, Hradec Kralove, Czech Republic). All animals were fed with a standard assorted A1 food (Ryhos, Novy Rychnov, Czech Republic) with equal amounts twice a day and had free access to a drinking water.

\subsection{Design of the Study}

Experimental pigs were randomly divided into two groups (six animals in Group A, six animals in Group B). All procedures were carried out under general anaesthesia. Intramuscular injections of ketamine $(20 \mathrm{mg}$ per kg; Narkamon, Spofa, Praha, Czech Republic) and azaperone (2.2 mg per kg; Stresnil, Janssen Animal Health, Saunderton, UK) were used as an induction of the anaesthesia in all animals. Intravenous infusion of propofol (AstraZeneca AB, Stockholm, Sweden) was used for subsequent maintenance of general anaesthesia. Heart rate and pulse oximetry were monitored throughout the experiments.

DSS was administered to overnight fasting animals in a dietary bolus in the morning at 7 a.m. for 7 days ( $10 \mathrm{~g}$ per day) to 6 out of 12 animals (Group B). Galantamine hydrobromide was administrated in the morning at 7 a.m. as a single intragastric dose (Group A: $24 \mathrm{mg}$ ) without previous DSS and after previous administration of DSS (Group B; $24 \mathrm{mg}$ of galantamine). The whole dose of galantamine was administrated endoscopically, using a video-gastroscope GIF-Q180 (Olympus Optical Co, Tokyo, Japan) dedicated for animal use only. Dextran sodium sulphate salt was purchased from Sigma-Aldrich (Praha, Czech Republic). Galantamine hydrobromide was purchased from Mylan Pharmaceuticals (Praha, Czech Republic).

Our original method of porcine surface EGG was published already [33]. We used six active self-adhesive electrodes placed on the upper part of the abdomen, the 7th basal electrode was placed to the left of the middle sternum. A special abdominal belt enabled to identify artefacts caused by breathing and body movements (Figure 11).

EGG recording was accomplished by means of the EGG Stand (MMS, Enschede, the Netherlands). Basal recording (within 15 min before galantamine administration) and study recordings after galantamine administration (throughout $300 \mathrm{~min}$ ) were evaluated by an MMS software (version 8.19). Running spectral analysis was used for a standard evaluation of EGG. Results were conveyed as dominant frequency of gastric slow waves (DF; cycles per minute—cpm) and power analysis (areas of amplitudes; $\mu \mathrm{V}^{2}$ ). 


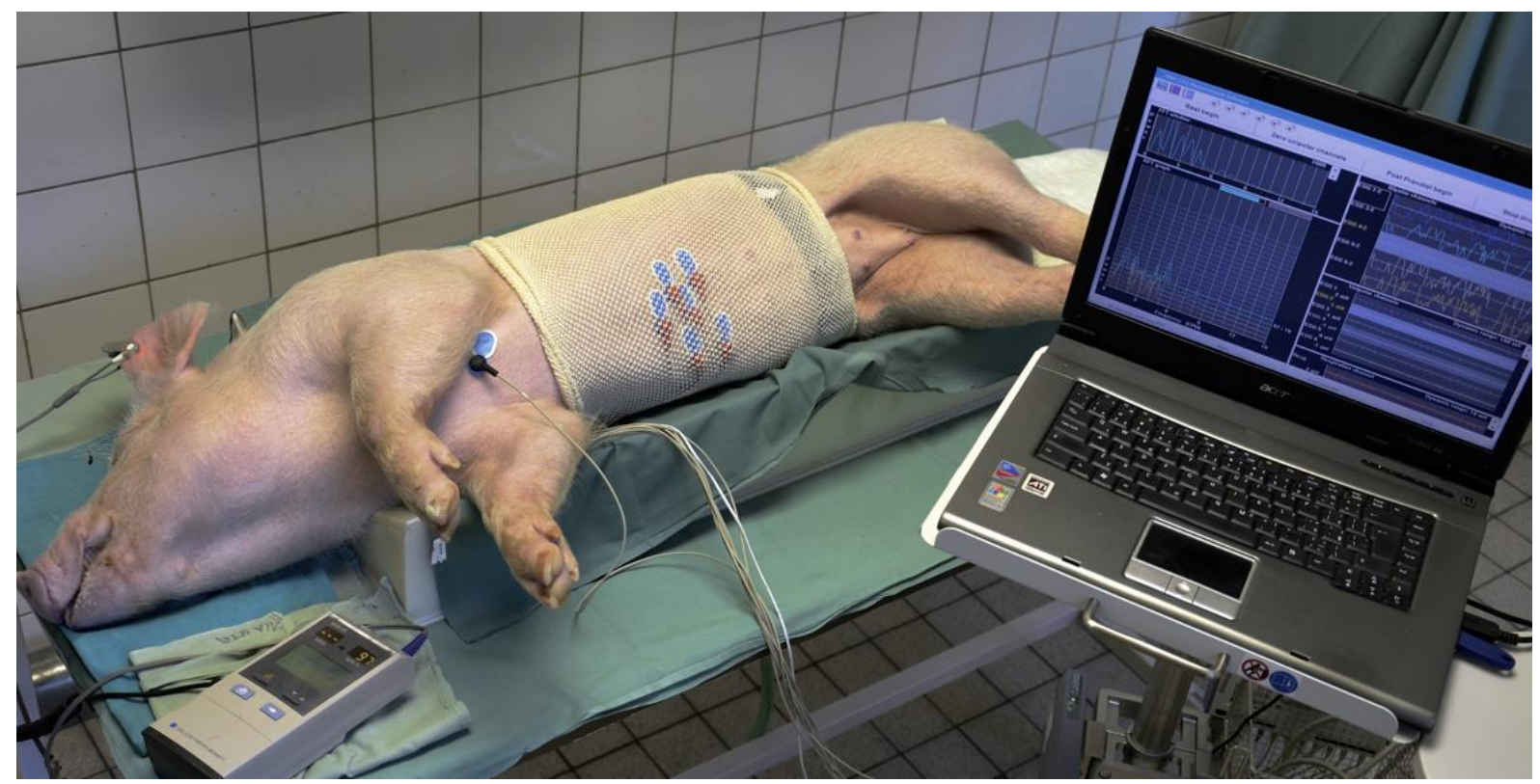

Figure 11. Arrangement of electrogastrography in experimental pigs. All recordings were accomplished under general propofol anaesthesia. Monitoring of vital functions was performed throughout the procedures.

Wireless capsule enteroscopy was performed on Day 8 in six animals of Group B. The investigation was performed by means of a CapsoCam system (CapsoVision, Saratoga, USA) which combines four camera images into a seamless $360^{\circ}$ panoramic view of the small bowel. Capsules were introduced endoscopically into the duodenum by means of a special delivery system (AdvanCE, US Endoscopy, Mentor, OH, USA). After the examination had been completed, endoscopic capsules were captured and images were evaluated by a dedicated software. Capsule enteroscopy was also used for the assessment of small bowel transit time (time between the first acquired endoscopic image of the duodenum and the last image of the ileo-caecal valve) [40].

\subsection{Statistical Analysis}

Data was statistically treated by means of descriptive statistics and Mann-Whitney rank sum test using the SigmaStat software (Version 3.1, Jandel Corp, Erkrath, Germany).

\subsection{Ethics}

The Project was approved by the Institutional Review Board of the Animal Care Committee of the University of Defence (Protocol Number MO 171673/2019-684800), Faculty of Military Health Sciences, Hradec Kralove, Czech Republic. The study was conducted in accordance with the policy for experimental and clinical studies [47]. Animals were held and treated in conformity with the European Convention for the Protection of Vertebrate Animals [48].

\section{Conclusions}

Galantamine alone revealed an unfavourable effect on porcine myoelectric activity assessed by gastric power. It can be a plausible explanation of galantamine-associated dyspepsia in humans. The decline in power was more prominent in the group with DSS pre-treatment. That may indicate that an underlying disease and/or a drug-induced gastrointestinal injury in elderly humans can aggravated the effect of galantamine on gastric myoelectric activity.

Author Contributions: J.B. conceived, designed and supervised the experiments, performed gastrointestinal endoscopy and electrogastrography, evaluated study results, performed statistical analysis, 
wrote the manuscript and secured funding. I.T. designed and supervised the experiments, performed gastrointestinal endoscopy and wireless capsule enteroscopy, and evaluated study results. J.K. consulted on experimental methods, served as a mentor in the design and performance of the research, coordinated the study and revised drafts of the manuscript. V.R. secured experimental work in animal laboratory. D.K. evaluated and discussed study results and revised drafts of the manuscript. M.V. participated in the study design and evaluated study results. S.R. participated in the study design and evaluated study results. V.K. assisted with gastrointestinal endoscopy and provided technical support. J.Z.K. supervised the findings of the work, evaluated and discussed results. All authors have read and agreed to the published version of the manuscript.

Funding: The work was funded by GACR (Czech Science Foundation; Grant Number 18-13283S). The funder had no role in study design and collection, analysis, and interpretation of data, or preparation of the manuscript.

Institutional Review Board Statement: The study was conducted according to the guidelines of the Declaration of Helsinki, and approved by the Institutional Review Board of the Animal Care Committee of the University of Defence (Protocol Number MO 171673/2019-684800), Faculty of Military Health Sciences, Hradec Kralove, Czech Republic. The study was conducted in accordance with the policy for experimental and clinical studies.

Informed Consent Statement: Not applicable.

Data Availability Statement: Availability of data and materials: all data generated or analysed during this study are included in this article.

Acknowledgments: Authors are much obliged to Eva Peterova, Martina Chladkova and Veronika Balaskova for their brilliant skills and excellent technical cooperation.

Conflicts of Interest: The authors declare no conflict of interest.

\section{References}

1. Tan, C.C.; Yu, J.T.; Wang, H.F.; Tan, M.S.; Meng, X.F.; Wang, C.; Jiang, T.; Zhu, X.C.; Tan, L. Efficacy and safety of donepezil, galantamine, rivastigmine, and memantine for the treatment of Alzheimer's disease: A systematic review and meta-analysis. $J$. Alzheimers Dis. 2014, 41, 615-631. [CrossRef]

2. Hager, K.; Baseman, A.S.; Nye, J.S.; Brashear, H.R.; Han, J.; Sano, M.; Davis, B.; Richards, H.M. Effects of galantamine in a 2-year, randomized, placebo-controlled study in Alzheimer's disease. Neuropsychiatr. Dis. Treat. 2014, 10, 391-401. [PubMed]

3. Korabecny, J.; Nepovimova, E.; Cikankova, T.; Spilovska, K.; Vaskova, L.; Mezeiova, E.; Kuca, K.; Hroudova, J. Newly developed drugs for Alzheimer's disease in relation to energy metabolism, cholinergic and monoaminergic neurotransmission. Neuroscience 2018, 370, 191-206. [CrossRef] [PubMed]

4. Tricco, A.C.; Ashoor, H.M.; Soobiah, C.; Rios, P.; Veroniki, A.A.; Hamid, J.S.; Ivory, J.D.; Khan, P.A.; Yazdi, F.; Ghassemi, M.; et al. Comparative effectiveness and safety of cognitive enhancers for treating Alzheimer's disease: Systematic review and network metaanalysis. J. Am. Geriatr. Soc. 2018, 66, 170-178. [CrossRef] [PubMed]

5. Pohanka, M. Inhibitors of cholinesterases in pharmacology: The current trends. Mini Rev. Med. Chem. 2020, $20,1532-1542$. [CrossRef] [PubMed]

6. Lilienfeld, S. Galantamine: A novel cholinergic drug with a unique dual mode of action for the treatment of patients with Alzheimer's disease. CNS Drug Rev. 2002, 8, 159-176. [CrossRef]

7. Scott, L.J.; Goa, K.L. Galantamine: A review of its use in Alzheimer's disease. Drugs 2000, 60, 1095-1122. [CrossRef] [PubMed]

8. Zarotsky, V.; Sramek, J.J.; Cutler, N.R. Galantamine hydrobromide: An agent for Alzheimer's disease. Am. J. Health Syst. Pharm. 2003, 60, 446-452. [CrossRef] [PubMed]

9. Hughes, A.; Musher, J.; Thomas, S.K.; Beusterien, K.M.; Strunk, B.; Arcona, S. Gastrointestinal adverse events in a general population sample of nursing home residents taking cholinesterase inhibitors. Consult. Pharm. 2004, 19, 713-720. [CrossRef]

10. Loy, C.; Schneider, L. Galantamine for Alzheimer's disease. Cochrane Database Syst. Rev. 2004, CD001747. [CrossRef]

11. Orgogozo, J.M.; Small, G.W.; Hammond, G.; Van Baelen, B.; Schwalen, S. Effects of galantamine in patients with mild Alzheimer's disease. Curr. Med. Res. Opin. 2004, 20, 1815-1820. [CrossRef]

12. Birks, J.; Craig, D. Galantamine for vascular cognitive impairment. Cochrane Database Syst. Rev. 2006, CD004746. [CrossRef]

13. Prvulovic, D.; Hampel, H.; Pantel, J. Galantamine for Alzheimer's disease. Expert Opin. Drug Metab. Toxicol. 2010, 6, 345-354. [CrossRef] [PubMed]

14. Haake, A.; Nguyen, K.; Friedman, L.; Chakkamparambil, B.; Grossberg, G.T. An update on the utility and safety of cholinesterase inhibitors for the treatment of Alzheimer's disease. Expert Opin. Drug Saf. 2020, 19, 147-157. [CrossRef] [PubMed]

15. Tamaru, T.; Kobayashi, H.; Kishimoto, S.; Kajiyama, G.; Shimamoto, F.; Brown, W.R. Histochemical study of colonic cancer in experimental colitis of rats. Dig. Dis. Sci. 1993, 38, 529-537. [CrossRef] [PubMed] 
16. Dieleman, L.A.; Ridwan, B.U.; Tennyson, G.S.; Beagley, K.W.; Bucy, R.P.; Elson, C.O. Dextran sulfate sodium-induced colitis occurs in severe combined immunodeficient mice. Gastroenterology 1994, 107, 1643-1652. [CrossRef]

17. Ni, J.; Chen, S.F.; Hollander, D. Effects of dextran sulphate sodium on intestinal epithelial cells and intestinal lymphocytes. Gut 1996, 39, 234-241. [CrossRef]

18. Kim, C.J.; Kovacs-Nolan, J.A.; Yang, C.; Archbold, T.; Fan, M.Z.; Mine, Y. 1-Tryptophan exhibits therapeutic function in a porcine model of dextran sodium sulfate (DSS)-induced colitis. J. Nutr. Biochem. 2010, 21, 468-475. [CrossRef]

19. Lackeyram, D.; Mine, Y.; Archbold, T.; Fan, M.Z. The small intestinal apical hydrolase activities are decreased in the piglet with bowel inflammation induced by dextran sodium sulfate. J. Anim. Sci. 2012, 90 (Suppl. 4), 287-289. [CrossRef]

20. Ibuki, M.; Fukui, K.; Kanatani, H.; Mine, Y. Anti-inflammatory effects of mannanase-hydrolyzed copra meal in a porcine model of colitis. J. Vet. Med. Sci. 2014, 76, 645-651. [CrossRef]

21. Chassaing, B.; Aitken, J.D.; Malleshappa, M.; Vijay-Kumar, M. Dextran sulfate sodium (DSS)-induced colitis in mice. Curr. Protoc. Immunol. 2014, 104, 15.25.1-15.25.14. [CrossRef] [PubMed]

22. Martin, J.C.; Bériou, G.; Josien, R. Dextran sulfate sodium (DSS)-induced acute colitis in the rat. Methods Mol. Biol. 2016, 1371, 197-203.

23. Parang, B.; Barrett, C.W.; Williams, C.S. AOM/DSS model of colitis-associated cancer. Methods Mol. Biol. 2016, 1422, 297-307. [PubMed]

24. Lackeyram, D.; Young, D.; Kim, C.J.; Yang, C.; Archbold, T.L.; Mine, Y.; Fan, M.Z. Interleukin-10 is differentially expressed in the small intestine and the colon experiencing chronic inflammation and ulcerative colitis induced by dextran sodium sulfate in young pigs. Physiol. Res. 2017, 66, 147-162. [CrossRef]

25. Nielsen, T.S.; Fredborg, M.; Theil, P.K.; Yue, Y.; Bruhn, L.V.; Andersen, V.; Purup, S. Dietary red meat adversely affects disease severity in a pig model of DSS-induced colitis despite reduction in colonic pro-inflammatory gene expression. Nutrients 2020, 12, 1728. [CrossRef]

26. Tacheci, I.; Kvetina, J.; Kunes, M.; Edakkanambeth Varayil, J.; Ali, S.M.; Pavlik, M.; Kopacova, M.; Rejchrt, S.; Bures, J.; Pleskot, M. Electrogastrography in experimental pigs: The influence of gastrointestinal injury induced by dextran sodium sulphate on porcine gastric erythromycin-stimulated myoelectric activity. Neuro Endocrinol. Lett. 2011, 32 (Suppl. 1), 131-136. [PubMed]

27. Chen, J.Z.; McCallum, R.W. (Eds.) Electrogastrography. In Principles and Applications; Raven Press: New York, NY, USA, 1994.

28. Parkman, H.P.; Hasler, W.L.; Barnett, J.L.; Eaker, E.Y.; American Motility Society Clinical GI Motility Testing Task Force. Electrogastrography: A document prepared by the gastric section of the American Motility Society Clinical GI Motility Testing Task Force. Neurogastroenterol. Motil. 2003, 15, 89-102. [CrossRef]

29. Koch, K.L.; Stern, R.M. Handbook of Electrogastrography; Oxford University Press: Oxford, UK, 2004.

30. Bures, J.; Kabelac, K.; Kopacova, M.; Vorisek, V.; Siroky, M.; Palicka, V.; Rejchrt, S. Electrogastrography in patients with Roux-en-Y reconstruction after previous Billroth gastrectomy. Hepatogastroenterology 2008, 55, 1492-1496. [PubMed]

31. Murakami, H.; Matsumoto, H.; Ueno, D.; Kawai, A.; Ensako, T.; Kaida, Y.; Abe, T.; Kubota, H.; Higashida, M.; Nakashima, H.; et al. Current status of multichannel electrogastrography and examples of its use. J. Smooth Muscle Res. 2013, 49, 78-88. [CrossRef] [PubMed]

32. Wolpert, N.; Rebollo, I.; Tallon-Baudry, C. Electrogastrography for psychophysiological research: Practical considerations, analysis pipeline, and normative data in a large sample. Psychophysiology 2020, 57, e13599. [CrossRef]

33. Bures, J.; Kvetina, J.; Radochova, V.; Tacheci, I.; Peterova, E.; Herman, D.; Dolezal, R.; Kopacova, M.; Rejchrt, S.; Douda, T.; et al. The pharmacokinetic parameters and the effect of a single and repeated doses of memantine on gastric myoelectric activity in experimental pigs. PLoS ONE 2020, 15, e0227781. [CrossRef] [PubMed]

34. Bures, J.; Kvetina, J.; Tacheci, I.; Pavlik, M.; Kunes, M.; Rejchrt, S.; Kuca, K.; Kopacova, M. The effect of different doses of atropine on gastric myoelectrical activity in fasting experimental pigs. J. Appl. Biomed. 2015, 13, 273-277. [CrossRef]

35. Bures, J.; Kvetina, J.; Pavlik, M.; Kunes, M.; Kopacova, M.; Rejchrt, S.; Jun, D.; Hrabinova, M.; Kuca, K.; Tachecí, I. Impact of paraoxon followed by acetylcholinesterase reactivator HI-6 on gastric myoelectric activity in experimental pigs. Neuro Endocrinol. Lett. 2013, 34 (Suppl. 2), 79-83.

36. Bures, J.; Jun, D.; Hrabinova, M.; Tacheci, I.; Kvetina, J.; Pavlik, M.; Rejchrt, S.; Douda, T.; Kunes, M.; Kuca, K.; et al. Impact of tacrine and 7-methoxytacrine on gastric myoelectrical activity assessed using electrogastrography in experimental pigs. Neuro Endocrinol. Lett. 2015, 36 (Suppl. 1), 150-155.

37. Kararli, T.T. Comparison of the gastrointestinal anatomy, physiology, and biochemistry of humans and commonly used laboratory animals. Biopharm. Drug Dispos. 1995, 16, 351-380. [CrossRef]

38. Gonzalez, L.M.; Moeser, A.J.; Blikslager, A.T. Porcine models of digestive disease: The future of large animal translational research. Transl. Res. 2015, 166, 12-27. [CrossRef]

39. Xiao, Y.; Yan, H.; Diao, H.; Yu, B.; He, J.; Yu, J.; Zheng, P.; Mao, X.; Luo, Y.; Chen, D. Early gut microbiota intervention suppresses DSS-induced inflammatory responses by deactivating TLR/NLR signalling in pigs. Sci. Rep. 2017, 7, 3224. [CrossRef]

40. Bures, J.; Tacheci, I.; Kvetina, J.; Radochova, V.; Prchal, L.; Kohoutova, D.; Valis, M.; Novak, M.; Dolezal, R.; Kopacova, M.; et al. The impact of dextran sodium sulfate-induced gastrointestinal injury on the pharmacokinetic parameters of donepezil and its active metabolite 6-O-desmethyldonepezil, and gastric myoelectric activity in experimental pigs. Molecules 2021, 26, 2160 [CrossRef] [PubMed] 
41. Parkman, H.P.; Trate, D.M.; Knight, L.C.; Brown, K.L.; Maurer, A.H.; Fisher, R.S. Cholinergic effects on human gastric motility. Gut 1999, 45, 346-354. [CrossRef] [PubMed]

42. Brown, J.H.; Taylor, P. Muscarinic receptor agonists and antagonists. In Goodman \& Gilman's Pharmacological Basis of Therapeutics; Brunton, L., Lazo, J.S., Parker, K.L., Eds.; McGraw-Hill: New York, NY, USA, 2006; pp. 183-200.

43. Kvetina, J.; Tacheci, I.; Pavlik, M.; Kopacova, M.; Rejchrt, S.; Douda, T.; Kunes, M.; Bures, J. Use of electrogastrography in preclinical studies of cholinergic and anticholinergic agents in experimental pigs. Physiol. Res. 2015, 64 (Suppl. 5), S647-S652. [CrossRef] [PubMed]

44. Turiiski, V.I.; Krustev, A.D.; Sirakov, V.N.; Getova, D.P. In vivo and in vitro study of the influence of the anticholinesterase drug galantamine on motor and evacuative functions of rat gastrointestinal tract. Eur. J. Pharmacol. 2004, 498, 233-239. [CrossRef] [PubMed]

45. Vigneault, P.; Bourgault, S.; Kaddar, N.; Caillier, B.; Pilote, S.; Patoine, D.; Simard, C.; Drolet, B. Galantamine (Reminyl) delays cardiac ventricular repolarization and prolongs the QT interval by blocking the HERG current. Eur. J. Pharmacol. 2012, 681, 68-74. [CrossRef] [PubMed]

46. Tacheci, I.; Radochova, V.; Kvetina, J.; Rejchrt, S.; Kopacova, M.; Bures, J. Oesophageal manometry in experimental pigs: Methods and initial experience. Acta Med. 2015, 58, 131-134. [CrossRef] [PubMed]

47. Tveden-Nyborg, P.; Bergmann, T.K.; Lykkesfeldt, J. Basic \& clinical pharmacology \& toxicology policy for experimental and clinical studies. Basic Clin. Pharmacol. Toxicol. 2018, 123, 233-235.

48. Explanatory Report on the European Convention for the Protection of Vertebrate Animals Used for Experimental and Other Scientific Purposes (ETS 123); Council of Europe: Strasbourg, France, 2009. 